\title{
Considerações sobre os cursos de formação de professores e o componente estágio supervisionado, na legislação educacional brasileira
}

\begin{abstract}
Resumo: O presente artigo tece algumas considerações acerca da legislação atual, especificamente a Resoluções n ${ }^{\circ} 1$ e n ${ }^{0} 2$ de 18 e 19 de fevereiro de 2002, respectivamente, sobre o componente estágio supervisionado nos cursos de formação de professores. A referida legislação não contempla especificidades refletidas por pesquisadores da área de formação de professores sobre a formação docente e identidade profissional (PICONEZ, 1999; PIMENTA; LIMA, 2007 entre outros) nem veicula estes cursos como um campo de conhecimento que está atrelado à valorização da profissão docente, à educação como um ato político e à relação entre a universidade e a escola de educação básica, possibilidades veiculadas no componente curricular estágio supervisionado. Palavras-chave: Estágio supervisionado. Formação de formadores de docentes. Legislação Federal de Ensino.
\end{abstract}

\section{O estágio supervisionado e formação de professores}

O componente curricular estágio supervisionado nos cursos de formação de professores tem sido objeto de estudo por muitos pesquisadores da área de formação de professores, de cursos de pedagogia e, em específico, das disciplinas de didática e práticas de ensino. As pesquisas e estudos estão atrelados ao caráter e ao espaço que o estágio supervisionado tem assumido nos projetos pedagógicos e sobre as possibilidades de se construir como um campo formativo propiciador de mudanças, tanto na universidade como na educação básica, numa proposta de superação da dicotomia entre a teoria e a prática.

É notório que o estágio supervisionado tem se constituído um dos suportes para a análise sobre a pretensa superação entre a teoria e a prática e das nuances a partir dela desde o exercício da docência enquanto a identidade da profissão, a prática pedagógica, a relação dos cursos e a escola de educação básica.

Em artigo publicado (SILVA, 2007) foi pesquisado e confirmado acerca do objeto de estudo o componente curricular estágio supervisionado, o que tem sido produzido cientificamente:
Arlete Vieira Silva

Doutoranda do Programa de PósGraduação em

Educação e Contemporaneidade UNEB, BA.

Universidade Estadual de Santa Cruz (UESC)

arlete@uesc.br 
Neste contexto a questão teórico-prática da disciplina Estágio Supervisionado tornou-se objeto de estudo e de projetos de diferentes autores (Azevedo 1980; Candau; Lellis, 1983; Carvalho, 1985; Piconez, 1999; Pimenta, 1999; Pimenta; Lima, 2004; Lima, 2004 e outros) que propõem sob diferentes formas a unidade entre teoria e prática.

Estes autores denunciavam que as orientações do estágio eram dirigidas em função de atividades de programas a priori, sem que tenham surgido das discussões entre educador-educando, no cotidiano da sala de aula, da escola e da comunidade. Assim, o conhecimento da realidade escolar através dos estágios não favorecia as reflexões sobre uma prática criativa e transformadora, nem possibilitava a reconstrução ou definição de teorias que sustentassem o trabalho do professor.

Numa tentativa de elucidar novos percursos diante destas críticas acerca dos cursos de formação docente e do componente estágio supervisionado, propôs-se na legislação atual apresentar os encaminhamentos (im)postos para a formação inicial.

\section{Considerações sobre os cursos de formação de profes- sores na legislação educacional atual}

A Lei de Diretrizes e Bases da Educação Nacional (LDBEN n ${ }^{\circ}$ 9394/96) não discorre sobre o componente estágio supervisionado isoladamente, mas ao tratar da formação de professores, estabelece que o Conselho Nacional de Educação (CNE) deve definir as diretrizes curriculares para os cursos de graduação no Brasil. Nestes, há especificidades para os cursos de formação de professores. Assim, a Resolução CNE/CP n ${ }^{\circ} 1$ de 18 de fevereiro de 2002 institui Diretrizes Curriculares Nacionais para a Formação de Professores da Educação Básica, em nível superior, curso de licenciatura, de graduação plena e a Resolução CNE/CP nº 2 de 19 de fevereiro de 2002 institui a duração e a carga horária dos cursos de licenciatura de graduação plena, de formação de professores da Educação Básica, em nível superior.

A Resolução $n^{\circ}$ 01/2002 destaca em seu artigo $2^{\circ}$ sobre fundamentos da formação de professores:

\footnotetext{
I - o ensino visando à aprendizagem do aluno.
}

II - o acolhimento e o trato da diversidade.

64 R. FACED, Salvador, n.18, p.63-70, jul./dez. 2010 
III - o exercício de atividades de enriquecimento cultural.

IV - o aprimoramento em práticas investigativas.

V - a execução e a elaboração de projetos de desenvolvimento dos conteúdos curriculares.

VI - o uso de tecnologias da informação e da comunicação e de metodologias, estratégias e materiais de apoio inovadores.

VII - o desenvolvimento de hábitos de colaboração e de trabalho em equipe.

Pode se determinar neste elenco, inicialmente, a presença de diferentes encaminhamentos e neles o caráter conceitual e prático que lhes é inerente e que se coloca como indicativo para os cursos de formação de professores, ou seja, indicativos que devem aparecer para instrumentalizar os futuros educadores para o exercício da docência.

A reflexão e o destaque destes encaminhamentos, como o exercício de atividades [...], o aprimoramento [...], o uso [...], o desenvolvimento de hábitos [...], etc. está em constar apenas o norte para a composição curricular enquanto desempenho dos futuros professores e não concepções acerca da formação, da identidade do professor, por exemplo.

Não obstante parece que se revive a concepção tecnicista que se acreditava superada desde a década de 70 do século passado, onde o professor era tratado como um reprodutor de conhecimentos. Confirmando esta reflexão, a mesma resolução apresenta em seu artigo $3^{\circ}$, parágrafo $1^{\circ}$, a noção de competência. Esta noção está atrelada a um determinismo, ou seja, competência como concepção nuclear de orientação para os cursos de formação de professores.

Há declaradamente uma redução da atividade docente a um desempenho técnico, que pode ser identificado no destaque ao domínio de conhecimentos de áreas que preparam para o ensinar, para conduzir o ensino, uma verdadeira didática instrumental, segundo Pimenta e Lima (2007, p. 104).

Estas autoras advertem que:

O conceito de competência substitui o de saberes e conhecimentos e o de qualificação. Não se trata de mera questão conceitual. Essa substituição acarreta ônus para os professores, uma vez que os expropria de sua condição de sujeitos de seu conhecimento, e, conseqüentemente, ônus para a educação de qualidade de seus alunos. O discurso das competências anuncia um neotecnicismo entendido como um aperfeiçoamento do positivismo. 
Numa contradição com os saberes necessários à prática educativa (FREIRE, 1999), o termo competência e os saberes a ela atribuídos ajustam-se muito mais à qualificação, ou melhor, às exigências de qualificação para o trabalho docente, no local de trabalho. Assim sendo, a formação docente passa necessariamente, nesta perspectiva da noção de competência na resolução, para a construção de uma identidade do trabalhador para o local de trabalho e nele executar tarefas.

Ainda Cunningham e Hargreaves (apud PIMENTA; LIMA, 2007) advertem que a identidade do professor que precisa ser construída durante a formação docente não se limita a um executor de currículos, mas que a identidade que precisa ser construída é daqueles professores que elaboram, que definem, e reinterpretam os currículos a partir do que pensam, creem, valorizam, conforme as conclusões de suas pesquisas.

O artigo $3^{\circ}$, em seu parágrafo $2^{\circ}$, citação "C", trata dos "conteúdos como meio e suporte para a constituição das competências", ainda como sendo eles - os conteúdos o que deve ser considerado para o exercício profissional. Percebe-se que o termo competência neste momento está atrelado ao conteúdo e não é originado como conhecimento e informação para o trabalho docente, portanto. Sendo suporte e meio apenas, não supõe diagnóstico da realidade, não supõe os conhecimentos prévios, o contexto escolar de educação básica, as conquistas coletivas da categoria profissional, entre outros aspectos que definem o fazer pedagógico como ato político. (FREIRE, 1999)

Acrescente-se que estes aspectos precisam definir o projeto político-pedagógico numa construção dos pares no "chão de escola". O movimento, portanto, é inverso, são os saberes, os conteúdos que definirão possíveis competências (impostas, descritas em documentos) e não elas (as competências) que definirão os saberes e valorizarão os professores como produtores de saber.

\section{O componente curricular estágio supervisionado na legislação educacional atual}

O componente curricular estágio supervisionado, nos cursos de formação de professores, está descrito e apresentado como indicativo de que seja realizado na perspectiva da racionalidade técnica onde o desenvolvimento de competências profissionais 
deve colocar-se após o conhecimento científico básico e aplicado, pois dentro desta racionalidade não é possível aprender competências e capacidades de aplicação antes do conhecimento aplicável. (PÉREZ GOMES, 1992)

Piconez (1999) corrobora com este autor quando coloca a concepção que especificamente o componente Estágio Supervisionado foi sendo definido nos currículos dos cursos de licenciatura até a vigência da LDB 9394/96: uma disciplina de complementação, ou seja, seu papel era de oportunizar que o licenciando colocasse em prática o que foi aprendido para "complementar" a sua formação. Evidencia-se concretamente, além da concepção até na disposição da disciplina na matriz curricular, a dicotomia entre a teoria e a prática.

$\mathrm{Na}$ atual legislação educacional, especificamente as Resoluções CNE C/P n ${ }^{0} 1$ e 02/2002 já citadas, estas discussões não foram superadas. Desde as categorias espaço-tempo em que deve acontecer o estágio nos cursos de formação de professores até a carga horária a ele destinado, não contemplam ainda reflexões necessárias como esta superação entre a teoria e a prática, e como momento do exercício da docência e, ainda, a relação (interação) entre a universidade e a escola de educação básica.

Na distribuição de carga horária para os cursos de formação de professores, o componente estágio supervisionado aliado aos componentes de prática de ensino, as horas de atividades acadêmico- científicas e cultural aparecem como momentos e possibilidades de vivência da prática na prática em separado das horas das disciplinas de natureza científico-cultural. Esta separação nos projetos acadêmicos dos cursos de formação de professores é um demonstrativo de fragmentação entre o que é teórico e o que é prático.

Acrescente-se ainda a concepção de que a área considerada de formação pedagógica por estes suportes e inferências na escola de educação básica não é uma área de conhecimento nos referidos cursos.

Considerar todos os componentes curriculares dos cursos de formação de professores como áreas de conhecimento é conceber que este conhecimento se constrói num movimento dialético entre a escola de educação básica e a universidade e que os profissionais - futuros professores são intelectuais em permanente formação. 
O elenco da carga horária e a definição de componentes curriculares colocam o estágio supervisionado num determinado tempo que pode ser o necessário?! A definição do momento - segunda metade do curso, continua corroborando com a separação tanto das atividades práticas como das de natureza cientifico - cultural, pois ao definir o momento é dizer que os futuros professores precisam aprender primeiro para depois colocar em prática, logo:

[...] nem prática, nem teoria, apenas treinamento de competências e aprendizagem de práticas modelares. Essa visão contraria os princípios da pesquisa pedagógica sobre saberes e identidades de professores, avanços que podemos sistematizar como segue: o curso de formação e especificamente o estágio supervisionado tem a grande função de renovar nossa concepção não só a respeito da formação dos estagiários, mas de suas identidades, contribuições e papéis profissionais […]. (PIMENTA; LIMA, 2007, p. 87-88)

Pode-se concluir que o estágio supervisionado não se constitui uma possibilidade de rever concepções sobre a formação dos estagiários e a construção de suas identidades, contribuições e papéis profissionais como têm refletido vários pesquisadores acerca do papel e contribuição deste componente curricular nos cursos de formação de professores.

\section{Considerações e encaminhamentos finais}

Educadoras como Pimenta e Lima (2007) apontam em suas pesquisas no campo da formação de professores que a universidade é por excelência o espaço formativo da docência, e ainda que não é simples formar para o exercício da docência de qualidade. Uma alternativa é que neste espaço haja interação com a escola de educação básica. A pesquisa é o caminho metodológico para essa formação e a possibilidade de interação entre a universidade e a educação básica.

Alguns encaminhamentos são necessários para comprovar essa interação como o retorno daquilo que foi pesquisado, elaborado e re-elaborado a partir da presença do estagiário na escola de educação básica, em propostas de formação continuada para esta escola e a presença desta na universidade em propostas significativas de relato de experiências, por exemplo, ou ainda nas aulas de estágio supervisionado com a apresentação e discussão de temas pedagó-

68 R. FACED, Salvador, n.18, p.63-70, jul./dez. 2010 
gicos. A legitimação da universidade como espaço de formação se concretiza, portanto, a partir destes encaminhamentos, tanto para o aluno estagiário como para aquele educador de educação básica, que recebe o aluno estagiário, pois ambos se "formam" na prática.

Finalizando, pode-se concluir que a reflexão posta para este componente curricular é que, sendo um campo de formativo para futuros professores deve ser parte integrante de todo o projeto curricular do curso. É um período especial, pois, além da reflexão pela presença na educação básica, é possibilidade de mudança no lócus da universidade pela presença de um professor que embasado teoricamente é o orientador do processo formativo. Neste movimento e articulação, as diretrizes e os projetos são revistos e refletidos desde a base da formação - nos cursos de formação inicial de professores.

\title{
Considerations on the training courses for teachers and supervised practice component, the Brazilian educational legislation
}

\begin{abstract}
This paper presents some considerations about the current legislation, specifically Resolution No. 1 and No. 02, 18 and 19 February 2002 respectively on the supervised practice component of training courses for teachers. This legislation does not address specifics reflected by researchers in the field of teacher education on teacher education and professional identity (PICONEZ, 1999; PIMENTA; LIMA, 2004) or conveys these courses as a field of knowledge that is related to recovery the teaching profession, education as a political act and the relationship between the university and school institutions, possibilities conveyed in the curriculum component of supervised training.

Key Words: Internship programs. Teachers, Training of. Educational law and legislation.
\end{abstract}

\section{Referências}

AZEVEDO, L. M. F. de. O estágio supervisionado: uma análise crítica. 1980. Dissertação (Mestrado) - Pontifícia Universidade Católica do Rio de Janeiro, Rio de Janeiro, 1980.

BRASIL. Lei $n^{\circ} 9$ 394, 20 de dezembro de 1996. Estabelece as diretrizes e bases da educação nacional. Brasília, DF, 1996. Disponível em: < http:// portal.mec.gov.br/secad/arquivos/pdf/ldb.pdf> . Acesso em: 23 nov. 2009.

CARVALHO, I. M. O processo didático. Rio de Janeiro: FGV, 1985.

Conselho Federal de Educação (Brasil). Resolução no 1 de 18 de fevereiro de 2002. Institui Diretrizes Curriculares Nacionais para a Formação de Professores da Educação Básica, em nível superior, curso de licenciatura, 
de graduação plena. Disponível em: < < http://www.confef.org.br/extra/ juris/mostra_lei.asp?ID $=40>$. Acesso em: 23 nov. 2009.

. Resolução $n^{\circ} 2$ de 19 de fevereiro de 2002. Institui a duração e a carga horária dos cursos de licenciatura, de graduação plena, de formação de professores da Educação Básica em nível superior. Disponível em:<http://portal.mec.gov.br/cne/arquivos/pdf/CP022002. pdf >. Acesso em: 23 nov. 2009.

CUNNINGHAM, M.; HARGREAVES, L. Minority ethnic teachers' professional experiences: evidence from the Teacher Status Project. RR 853 London: DfES, 2007. (Research Report, n. 853) Disponível em: <https:// www.education.gov.uk/publications/eOrderingDownload/RR853.pdf> . Acesso em: 28 nov. 2011.

FREIRE, P. Pedagogia da autonomia: saberes necessários à prática educativa. São Paulo: Paz e Terra, 1999.

LIMA, M. do S. L. A hora da prática: reflexões sobre o estágio supervisionado e a ação docente. 4. ed. Fortaleza: Edições Demócrito Rocha; EdUECE, 2004.

PÉREZ GOMES, A. Formação dos professores da licenciatura: os professores e sua formação. Porto: Porto Editora 1992.

PICONEZ, S. A prática de ensino e o estágio supervisionado: a aproximação da realidade escolar e a prática da reflexão. In: (Org.). A prática de ensino e o estágio supervisionado. 3. ed. Campinas, SP: Papirus, 1999.

PIMENTA, S. G. P.; LIMA, M. do S. L. Estágio e docência. São Paulo: Cortez, 2007. (Saberes Pedagógicos)

SILVA, A. V. Estágio curricular supervisionado no curso de licenciatura: momentos de vivência da profissão professor nas escolas de educação básica. Revista Espaço Acadêmico, Maringá, PR, ano 7, n. 73, jun. 2007. Disponível em: <http://www.espacoacademico.com.br/073/73silva.htm http://www.espacoacademico.com.br/073/73silva.htm >. Acesso em: 25 nov. 2010.

Artigo submetido em 8/04/2010, aceito para publicação em 11/05/2011. 